Article

\title{
Digitalization and Business Activity. The Struggle to Catch Up in CEE Countries
}

\author{
Daniela Livia Trașcă ${ }^{1}$, George Marian Ștefan ${ }^{1, *}$, Daniela Nicoleta Sahlian ${ }^{2}$, Răzvan Hoinaru ${ }^{3}$ \\ and George-Laurențiu Șerban-Oprescu ${ }^{4, *}$ \\ 1 Department of Economics and Economic Policies, Bucharest University of Economic Studies, \\ 010734 Bucharest, Romania; daniela.trasca@economie.ase.ro \\ 2 Department of Accounting and Auditing, Bucharest University of Economic Studies, 010734 Bucharest, \\ Romania; daniela.sahlian@cig.ase.ro \\ 3 School of Business and Management, Queen Mary, University of London (QMUL), London E1 4NS, UK; \\ r.hoinaru@qmul.ac.uk \\ 4 Department of Economic Doctrines and Communication, Bucharest University of Economic Studies, \\ 010734 Bucharest, Romania \\ * Correspondence: george.stefan@economie.ase.ro (G.M.S.); george.serban@economie.ase.ro (G.-L.S,.-O.)
}

Received: 21 February 2019; Accepted: 4 April 2019; Published: 12 April 2019

\begin{abstract}
Increases in productivity and competitiveness of an economy are based mostly on the actions of companies in terms of providing technical capital to workers and of operations efficiency (management, financial, recruitment, finding markets and suppliers, internal and external communication, etc.) through digitalization. This paper deals with the way in which the economies and companies in Central and Eastern European (CEE) countries manage to adapt to the trend that started, mostly after 2000, in digitalization; also, it analyzes the extent to which an increase in the degree of business upgrading via integrating digital technology into the business model leads to a surge in economic performances (productivity, exports) and, consequently, to a greater attractivity to foreign capital flows.
\end{abstract}

Keywords: business digitalization; value added; digital agenda; technology; SMEs

\section{Introduction}

In order to remain competitive and to create higher value added, companies need to implement technological innovations and at the same time to attract and train employees to meet the new requirements imposed by the Fourth Industrial Revolution (so-called Industry 4.0), An essential component of which is the digitalization of business in all its aspects.

Rüßmann et al. mention that the Industry 4.0 transformation will facilitate obtaining and analyzing a large amount of data across machines, and will speed up production processes to create higher-quality goods at reduced costs. Thus, the authors conclude that "there will be an increase in manufacturing productivity, shift economics, foster industrial growth, and modify the profile of the workforce-ultimately changing the competitiveness of companies and regions" [1] (p. 6).

Parviainen et al. consider that "digitalization has been identified as one of the major trends changing society and business in the near- and long-term future the impact of digitalization will be major; it has been compared to the industrial revolution by several authors" [2] (p. 64). Citing E. Stolterman and A. C. Fors, Parviainen et al. affirm that the term digitization refers to "the action or process of digitizing; the conversion of analogue data (images, video and text) into digital form", while digitalization (or digital transformation according to the authors), "can be understood as the changes that the digital technology causes or influences in all aspects of human life" [2,3] (p. 689). Additionally, 
Kagermann sees digitization as "the continuous convergence of the real and virtual world and can be regarded as the main driver of innovations and changes in all sectors of our economy" [4].

Also, Rachinger et al. assume digitization as a process of converting analogue data into digital data sets and as a framework for digitalization (i.e., the exploitation of digital opportunities). In their view, digitalization means combining digital technologies (e.g., cloud technologies, sensors, big data, 3D printing) to ultimately create radically new goods and services [5].

In another study, published by Brennen and Kreiss, digitalization refers to "the adoption or increase in use of digital or computer technology by an organization, industry, country, etc." [6].

However, in our understanding, digitalization is closer to the comprehensive definition provided by i-scoop.eu, as a "tool" that "turns interactions, communications, business functions and business models into (more) digital ones which often boils down to a mix of digital and physical as in omnichannel customer service, integrated marketing or smart manufacturing with a mix of autonomous, semi-autonomous and manual operations" [7]. Also, another relevant source for the comparison between digitization and digitalization is the article published by Prause on SAP website (https: //news.sap.com) [8].

Also, as Rachinger et al. noted, digitalization has as primary root the term" digitization", representing the use of digital technologies having in mind to change a business model/products or services [5]. As reported by i-scoop.eu, digitization could be summed up in one sentence as "the transformation from analog to digital or digital representation of a physical item with the goal to digitize and automate processes or workflows" [7].

According to Novak et al. in a report for McKinsey and Company, in terms of public policies to be applied, there are several action areas that governments should focus on in order to benefit as much as possible from digitalization, by working together with other stakeholders, especially with businesses and individuals who impose the pace of change [9]. These are presented in Figure 1.

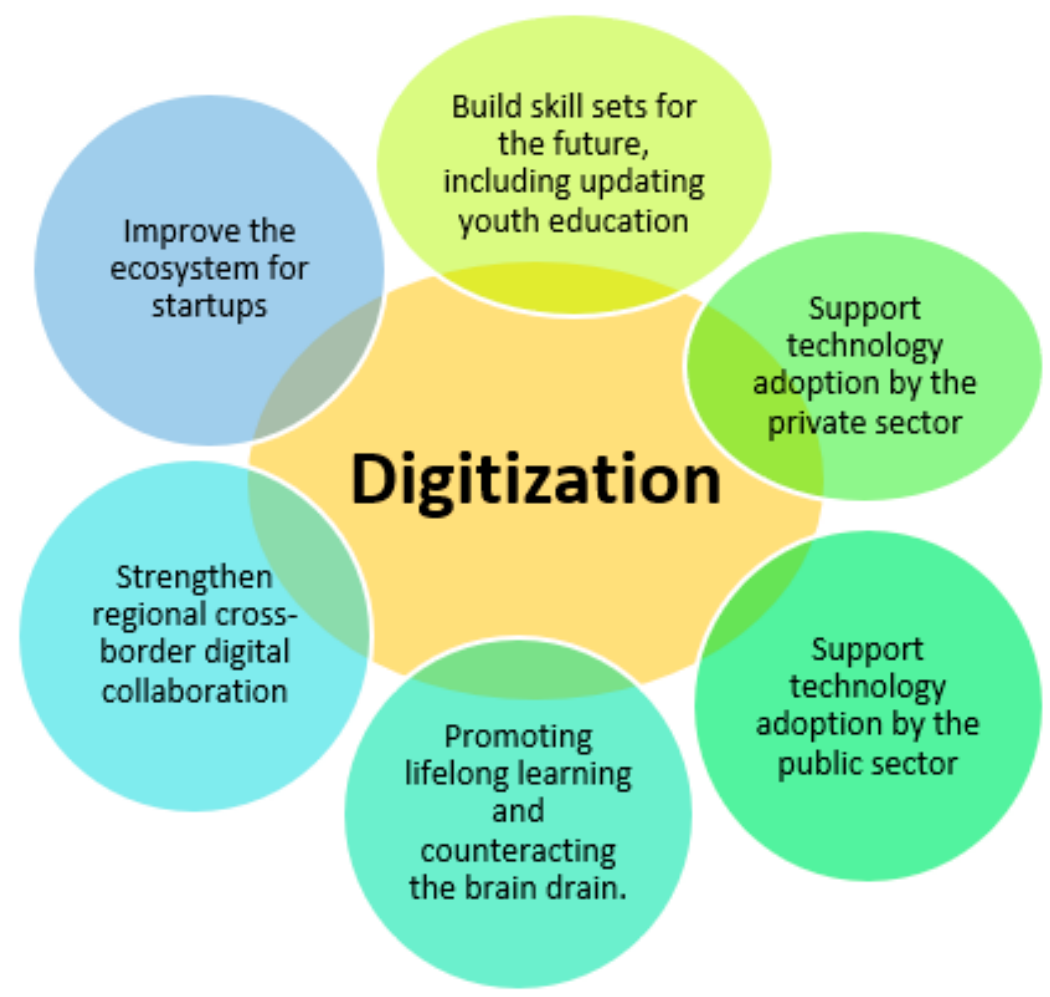

Figure 1. Digitalization policy areas based on Novak et al. [9].

Although all six dimensions identified by Novak et al. are important in terms of adapting to digitalization, this paper aims to analyze: (1) the evolution of the digitalization process among private 
companies; and (2) whether the higher adaptation level to digitization contributes to strengthening the ability of companies to generate greater added value and to attract financing.

In addition, Novak et al. show that, as far as youth education is concerned, public authorities should facilitate the development of digital infrastructure and such tools (for ex the use of VR or the promotion of online courses) and even greater emphasis should be put on information technology (IT) programming, entrepreneurship, as well as improving the communication skills of young people [9].

Two other relevant issues are aimed at STEM specialization in order to increase the recruitment base for the information technology and communications (ITC) sector (including attracting more women specialists) and, at the same time, to cooperate with domain-related companies to create internship programs/apprenticeships.

In this process, however, it should be highlighted that a key component should be the focus on efforts to analyze and diagnose the current state of the labor force, and also to forecast the necessary shift in skill sets for the future, e.g., develop a labor market model, identify sector shifts, and understand the gap between current and future skills" [9] (p. 64).

Finally, in terms of stimulating the extensive use of technology within companies, mainly small and medium enterprises (further SMEs), various tools are being suggested for governments to implement, such as:

(1) use of digital tools within small and medium enterprises, including easier access to non-refundable external funding (i.e., European Union (EU) funds) to finance the relevant private initiatives for digital tools implementation; and

(2) digitalization of the interaction between businesses and central/local governments, with direct effects on tax payments efficiency, higher tax compliance and significant time savings.

This paper is constructed as follows:

(i) A first section where we presented briefly the methodology followed during the research;

(ii) A literature review section on the importance of using digital technology within companies and the benefits of it;

(iii) Empirical analysis of the actual use of digitalization in Central and Eastern European (CEE) countries relative to EU28 average and important aspects regarding types of digitalization preferred by the firms in CEE countries as a main technology;

(iv) The final part of the paper examines if there is a contribution of the digitalization to their attractivity for the financial markets.

Chiefly, our aim is to understand how the economies and firms from selected Central and Eastern European countries manage to adapt to current digitalization trends and to analyze whether, by integrating digital technology into local small- and medium-enterprise (SME) business model, is there an improvement of their economic performances (in terms of more exports or greater productivity etc.), and if a greater interest in private equity investment flows towards these countries is displayed.

\section{Methodology}

The first part of the study starts with a critical analysis of the field literature highlighting both quantitative and qualitative studies on digitalization and the impact on business performance, with an emphasis on SMEs.

Also, we make use of an empirical analysis of the actual usage of digitalization in CEE countries relative to EU28 average. Based on data from European statistics office Eurostat and European Commission, we present main types of digitalization tools favored by CEE firms. Data were collected via the survey conducted by Eurostat during 2018 on a sample of 158,000 enterprises with at least 10 persons employed. In our study we analyze the performances of firms from Czech Republic, Bulgaria, Romania, Poland, Hungary, Latvia, Lithuania, Estonia and Croatia (abbreviated further CEE9). Furthermore, we conduct an in-depth analysis, aiming to observe how the integration of 
these digitalization pillars into small and medium enterprises activity influences different economic indicators, such as foreign direct investment (FDI) stock per capita, exports per capita, enterprises growth rates, labor productivity or gross value added. Finally, the last sections of the paper examine the capital flows to SMEs from the CEE9 and the contribution of the digitalization to their attractivity for the financial markets.

Bearing in mind the potential benefits of digitalization on the business environment on the one hand, and the evidence presented by other scholars (summarized below in Section 3) on the other hand, we proceed with three major research assumptions to direct our approach:

Assumption 1. A greater intensity of digitalization for SMEs is correlated with a larger share of high-growth companies.

Assumption 2. Integration of digital technology into business activity improves both productivity and exports of SMEs.

Assumption 3. A more pronounced digital technology intensity increases the attractivity of SMEs for foreign financial markets (through mergers and acquisitions (MEAs) and private equity investment).

\section{Literature Review: Digitalization and Enterprise Performance}

Parida et al. found that emerging literature on digitalization and business is relatively new. The first paper dates from 2012 and until September 2018 there have been published 106 studies in 73 international journals [10].

The development of digitalization within companies has been driven by increased Internet access and increased connectivity (almost limitless) between companies, individuals and public authorities. This phenomenon creates the environment in which technologies become available to businesses in order to share information and to automate internal activities (operations, functions) and companies' relations with suppliers and customers.

Intensifying the use of ITC technologies contributes to the increase of labor productivity at industrial level and to economic growth, being an essential condition for gaining competitive advantages on the global market and, at the same time, for the current economic development. Consequently, the European Commission [11] launched an initiative to digitalize European industry in order to help member states with incentives to develop digital innovation hubs at local level and to further support economic sectors to become more competitive.

According to the European Commission, efforts to digitalize European industry cover two key aspects: the development of the European digital infrastructure, and the improvement of the framework conditions for digital innovation. Also, the Commission considers that the manufacturing industry, and its connection to the services sector, plays an important role in the European economy, in the context of the New Industrial Revolution which is based on automatization, algorithms, robots, big data, etc. [11].

As emphasized by Rüßmann et al., there is a perpetual transformation of products, processes and business models following technologies development (Internet of Things, cloud computing, data analytics, robotics, etc.) while new industrial patterns emerge as global value chains adjust [1].

Tarute and Gatautis conclude that "there is a positive effect of information and communication technologies (ICT) on company performance in terms of productivity, profitability, market value and market share. Their findings highlighted that for best performances it is important to align ICT investments with internal capabilities and organizational processes" [12] (p. 7). As shown in Figure 2, the study identifies 9 main drivers for industrial development in the digital age [12]. 

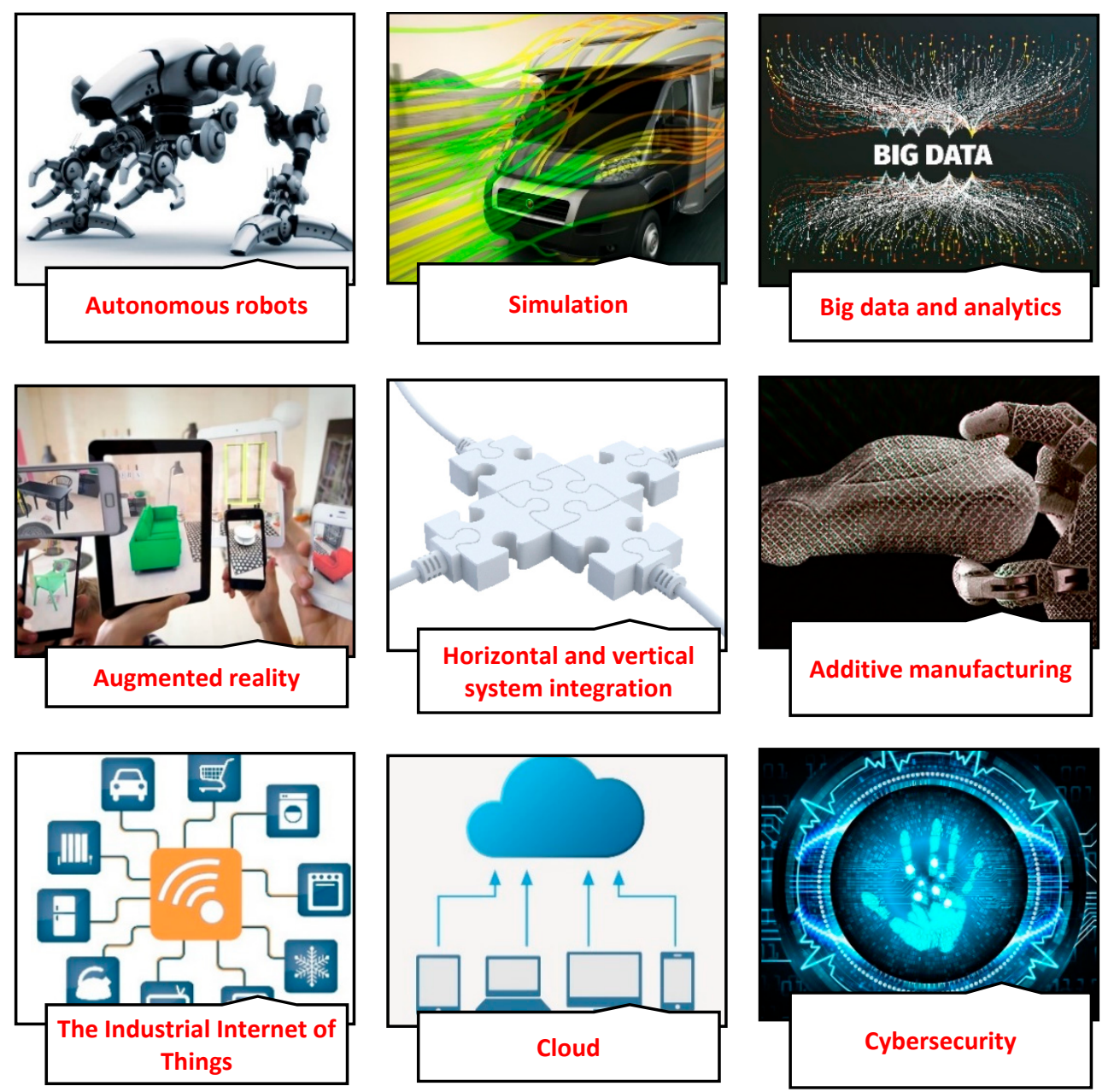

Figure 2. Industrial production in the digital age based on BCG [12].

Another study, published by Reichstein et al., claims that "firms must decide on their own how to benefit from new technologies caused by digitization" [13] (p. 294). Based on online interviews with more than 200 experts from the ITC sector (mainly from SMEs) within German-speaking countries (Germany, Austria and Switzerland), they tested six hypotheses regarding the impact of "efficiency, innovation, data privacy, mobility, new business models and human integration on the potential value of digitization aspects within firms" [13] (p. 289). In their study, Reichstein et al. have identified six working hypotheses: (1) "An improvement of efficiency positively influences the potential value of digitization" [13] (p. 289); (2) "An improvement of innovation processes positively influences the potential value of digitization" [13] (p. 289); (3) "Data security positively influences the potential value of digitization" [13] (p. 290); (4) "An improvement of mobility positively influences the potential value of digitization" [13] (p. 290); (5) "The generation of new business models positively influences the potential value of digitization" [13] (p. 290); (6) "Human involvement positively influences the potential value of digitization" [13] (p. 291).

According to their research, only three hypotheses have been confirmed by the structural equation model (SEM), namely efficiency, mobility and generation of new business models, with significant and positive impact on digitization [13].

\section{Empirical Evidence from European Union (EU28) Countries on Digitalization Tools Used by Small and Medium Enterprises (SMEs)}

In general, at European level, over the past five years, there has been an increasing integration of digital elements into the business dynamics of companies within the Member States. According 
to Eurostat, in the EU at the end of 2017, $93 \%$ of companies had access to a fixed broadband internet connection and $77 \%$ of them had their own website. Concerning Internet interaction, $45 \%$ of companies use social networks, $16 \%$ have multimedia content on their own website, $14 \%$ have blogs or micro-blogs, while 5\% have Wiki-based tools knowledge-sharing. Moreover, the most common reasons for the use of social media are to develop the enterprise's image or market products $(40 \%)$ and recruit employees $(23 \%)$.

The driving forces of digitalization are extremely important for the way European firms run their business, accomplish internal communication, or share information with business partners, government and customers. The same driving forces have a tremendous impact on reducing business operating expenditures (OPEX) such as payroll, office supplies, utilities, marketing or taxes.

Figure 3 highlights the use of different digital tools within European enterprises, measured by the European Commission using data from Eurostat-Community survey on ICT (covering 158,000 enterprises with at least 10 persons employed). The Digital Intensity score is based on observing how many out of 12 technologies are used by each enterprise. The basic list of main technologies used by companies includes: usage of internet by the majority of workers; access to ICT specialist skills; fixed broadband speed $>30 \mathrm{Mbps}$; mobile devices used by more than $20 \%$ of employees; the existence of a website; sophisticated functions featured on the website; presence on social media; e-sales that count for at least $1 \%$ of turnover; exploit the business-to-consumer (B2C) opportunities of web sales; pay to advertise on the internet; purchase cloud computing advanced services; send e-Invoices. According to their performance on these categories, companies are divided into four categories of digital intensity: Very Low (scores 0-3), Low (score 4-6), High (score 7-9), Very High (score 10-12).

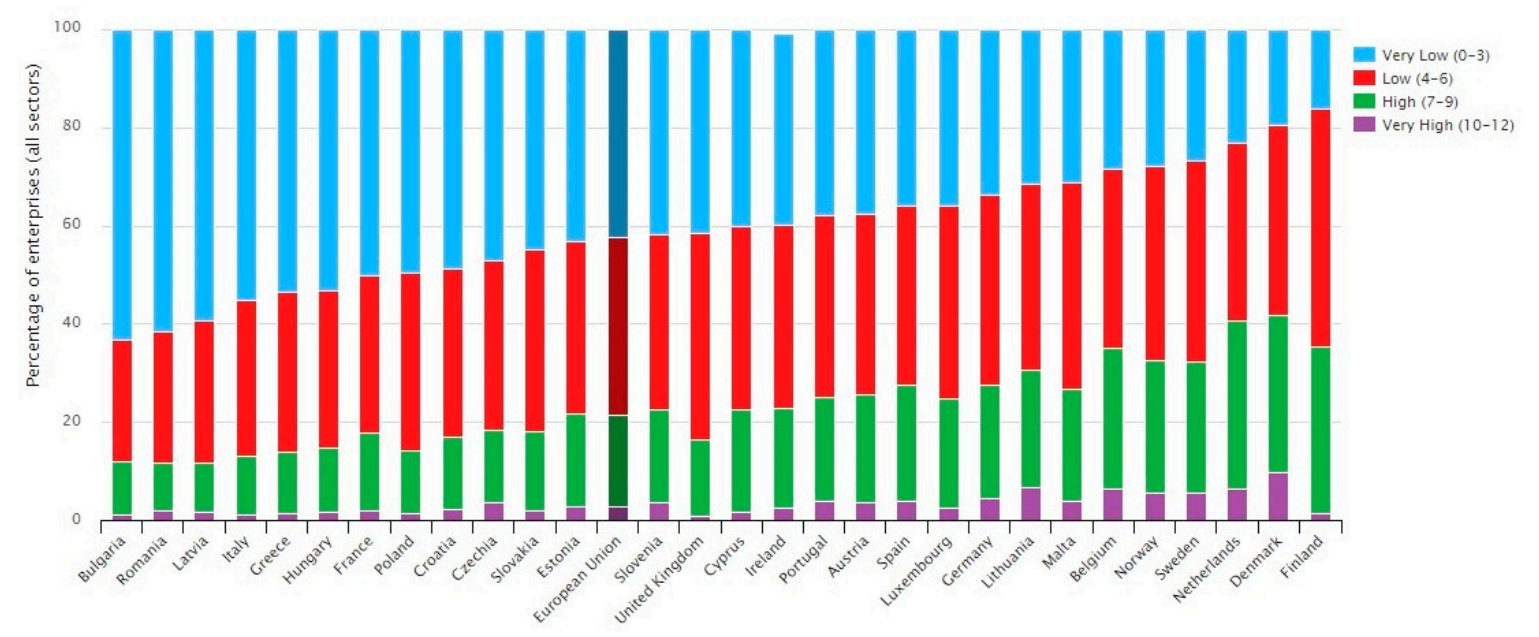

Figure 3. The Digital Intensity score for enterprises in Europe (2017) [14].

There is important heterogeneity among the member states, while Bulgaria, Romania, Latvia and Italy are the countries where most enterprises display a Very Low level of digital intensity. In these states more than $55 \%$ of companies from all activity sectors use a maximum of three technologies. At the other end of the spectrum, Finland, Denmark, Netherlands and Sweden perform best with a High level of digital intensity among businesses. However, at present time, the EU average points to a rather low to very low level of digital intensity: $42.4 \%$ of enterprises display a Very Low level of digital intensity, while $36.1 \%$ of enterprises show a Low level.

Using the European Commission-Digital Agenda Scoreboard key indicators as starting point, we evaluate how companies from EU28 integrate different digital tools within their business activity based on four important pillars presented in the table Table A1 from Appendix A. Similarly, in the next section of the paper we conduct an in-depth analysis, looking at how the integration of these pillars into SMEs activity influences economic indicators, such as foreign direct investment (FDI) stock per capita, exports per capita, SME growth rates, labor productivity or gross value added. 
As observed in the Table A2, the share of EU28 enterprises that used enterprise resource planning (ERP) software applications reached 34\% in 2017 (from 31\% in 2014), with a significant gap between small enterprises (28\%) and large enterprises (76\%). Also, 33\% of EU28 enterprises used customer relationship management (CRM) software applications in 2017, with a share among small enterprises $(30 \%)$ of roughly half the number for large enterprises $(62 \%)$.

Across the EU28 member states, $18 \%$ of enterprises made use of business processes that automatically linked them to suppliers and/or customers in 2017 as opposed to $17 \%$ in 2014 . There is also a difference between types of enterprises; only $15 \%$ of small enterprises use these features, well below the share recorded for large enterprises (47\%). In terms of radio frequency identification, in 2017 less than 1 in 10 (9\%) small enterprises from the EU28 used this technology, while the share for large enterprises was four times higher, $44 \%$.

Based on Eurostat data about e-commerce sales, one fifth (20\%) of all enterprises in the EU28 made e-commerce sales in 2016 ( +7 p.p. compared to 2008). Looking at the type/size of the enterprise, it seems that, in 2016, $44 \%$ of large enterprises, $29 \%$ of medium-sized enterprises and $18 \%$ of small enterprises made e-sales. At the same time, e-sales represented around $18 \%$ of the total turnover generated by EU28 companies, showing an increase by 6 p.p. between 2008 and 2016 .

\section{Empirical Evidence from CEE9 Countries on the Impact of Digitalization Tools Used by SMEs}

The benefits of digitalization are expected to penetrate all Member States, but currently-as Figure 3 shows-some EU countries gain more than others. This section analyses the differences between Eastern and Western states (a South-North countries analysis would be similar).

Thus, on the one hand, according to Alm et al. (2016), one can see the frontrunners (the group formed by Denmark, Belgium, Netherlands, Sweden, Ireland or Finland), where enterprises integrated to a greater extent in their operational activity tools related to ITC. On the other hand, the member states from CEE are well behind the leaders and below the EU average [15].

In line with Alm et al., "a significant part of GDP could increase due digitalization in the digital frontrunner nations for at least two reasons. Firstly, countries like Denmark, Ireland, Netherlands or Belgium are already highly focused on exports, thus increased in external trade will have a positive effect on exporting businesses. Secondly, they have a strong digital footprint, making them better prepared to benefit from digital cross-border commerce" [15] (p. 16). Furthermore, the study concludes that via full implementation of the European Digital Single Market only, their GDP growth rate could increase by $40 \%$ until 2020 even without any significant investment by national governments.

The effects of heterogeneity among CEE states and frontrunners is displayed in the differences recorded in terms of GDP per capita and SME labor productivity. In Figure 4 we underline the gap of productivity between CEE countries and the EU average. Productivity is computed as value added generated by the total number of SMEs per employee.

The SMEs from all 9 analyzed CEE countries perform below $60 \%$ of the EU average value added per employee, the most important gap being registered in Bulgaria $(26 \%$ of the EU SMEs average productivity) and Romania (29\%). Additionally, these are the countries with the lowest digital intensity of enterprises in the entire EU. Among the CEE states, Estonia displays the smallest gap relative to the EU average in terms of value added generated by an SME employee. In Estonia, productivity is about $40 \%$ lower than the EU average. As Figure 3 shows, Estonia alongside Lithuania displays the highest Digital Intensity score for enterprises when compared with all CEE peers.

Another dimension is the number of high-growth SMEs in CEE countries. According to the European Commission data, it seems that Hungary and Latvia have the largest number of high-growth SMEs in our sample. A high-growth enterprise is defined as an enterprise with average annualized growth in number of employees greater than $10 \%$ per year over a three-year period and having at least 10 employees at the start of the growth period. Also, as expected, the small and medium companies from CEE, except for Romania and Estonia, increased more than the EU average due to the catching-up process (Figure 4). 


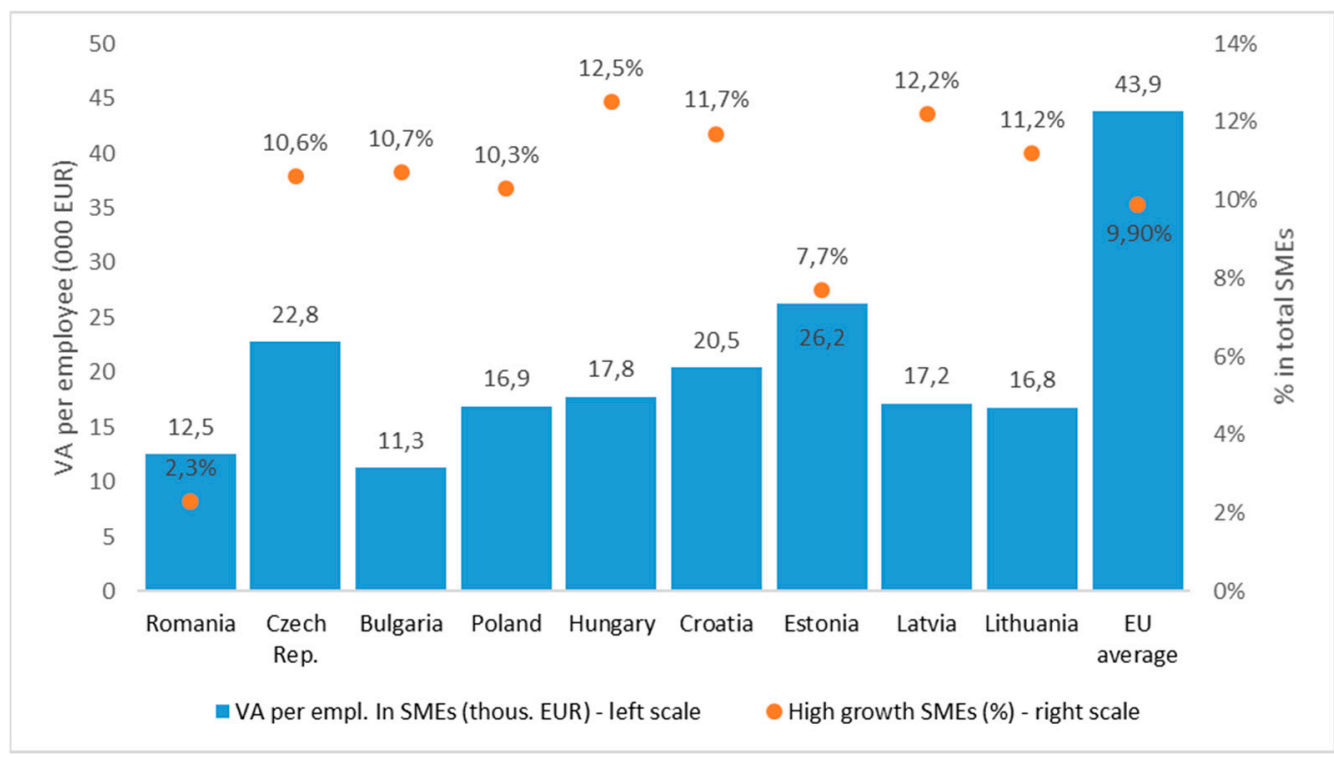

Figure 4. Value added and high growth small and medium enterprises (SMEs) in selected Central and Eastern European (CEE) countries-authors' processing based on European Commission data [14].

Starting from the relationship between productivity and digital intensity (Figure 5) we analyzed several aspects of SMEs performance related to the integration of digitization into the business model. This analysis follows the assumption that a higher degree of digitalization within a company should significantly improve its competitiveness, being directly correlated with other economic indicators such as: increase of sales, increase in productivity/value added per employee (as presented in Figure 6), or increased export value.

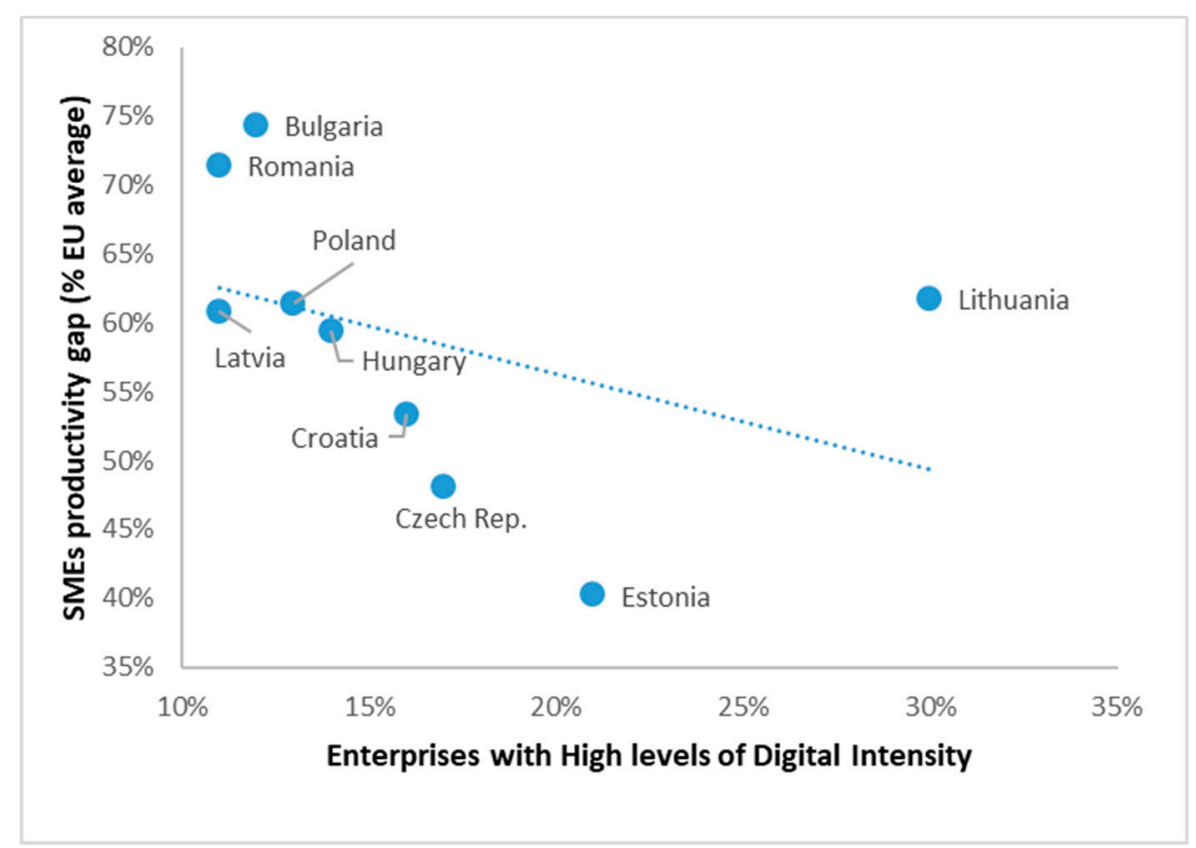

Figure 5. Productivity gap and Digital Intensity in CEE countries-authors' processing based on European Commission data [16]. 

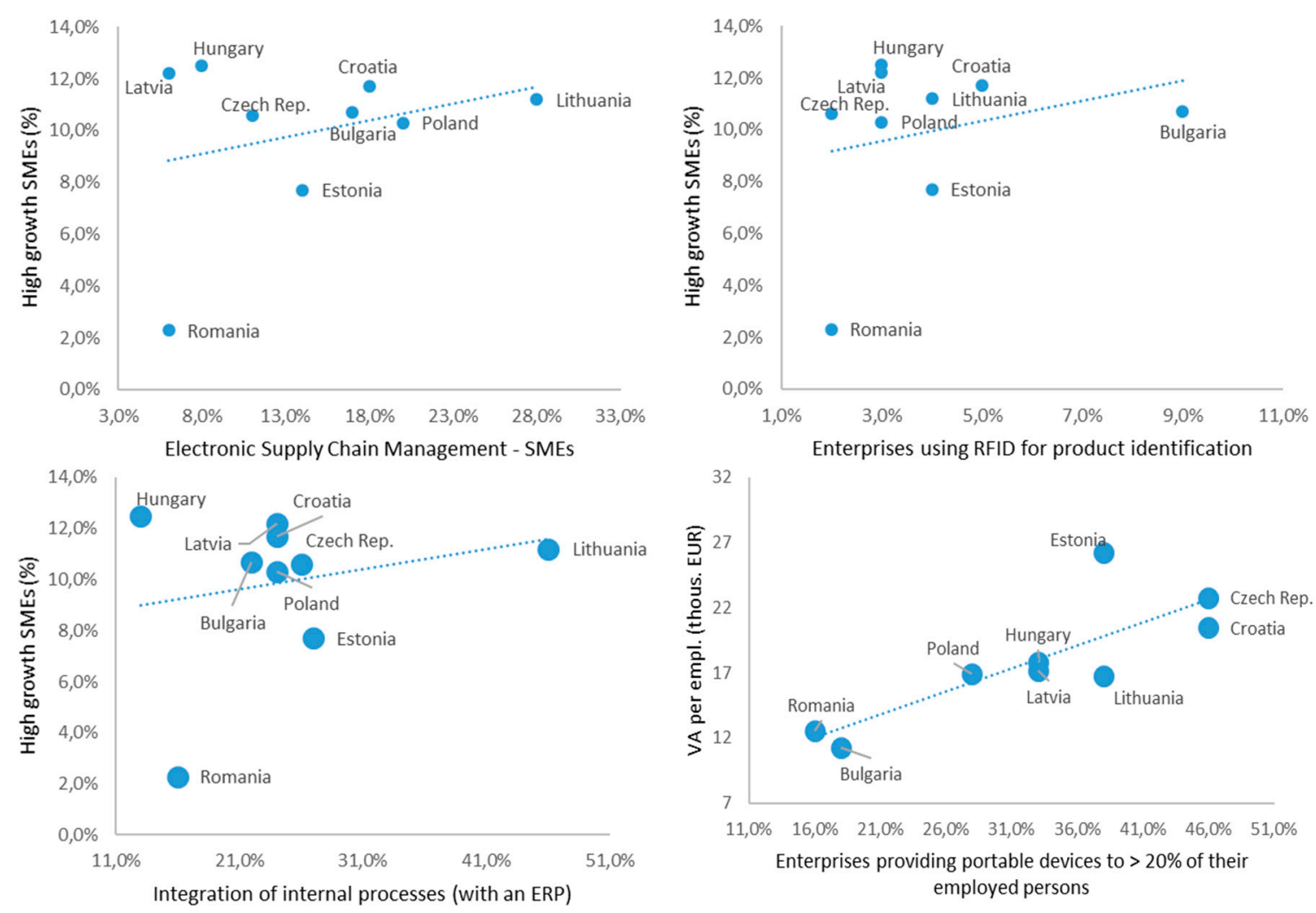

Figure 6. Digitalization contribution to SMEs' performance-authors' processing based on European Commission data [16].

Streamlining the internal processes or functions of private and public companies by means of digitalization (i.e., marketing, sales, accounting, logistics etc.) decreases the costs and improves competitiveness, facilitating access to foreign markets.

In general, exports are carried out by large companies (more than 250 employees) - transnationals - with easy access to finance for the development of marketing networks and the marketing of products overseas. As presented in Figure 7, based on Organization for Economic Cooperation and Development (OECD) data [17], large companies have a majority share of Romanian, Hungarian and Polish exports, and close to 50\% in the case of the Czech Republic and Bulgaria.

In addition, enhanced marketing capacity, for example, through the use of a more sophisticated website, has an important role to play in the ability of SMEs to sell on the domestic market and to export outside the home country; specifically when these are SMEs that, due to lack of funding and limited staff, cannot open their own headquarters on the foreign market. Accordingly, the countries in which SMEs are able to integrate components of digitalization in their business activities and acquire technological strength grow more and export more (Figure 8).

This assumption is valid in the case of Romania, Bulgaria, Poland and Hungary, countries that exhibit a low digital literacy rate and a low level of SMEs exports share of total exports. It is also important to note that although Latvia shows a high share of SMEs exports, the value of exports per SME employee is relatively low.

Finally, there seems to be a direct correlation between the exports of companies and the degree of sophistication of SMEs' websites; this correlation is valid for countries such as Hungary, Estonia or the Czech Republic. 


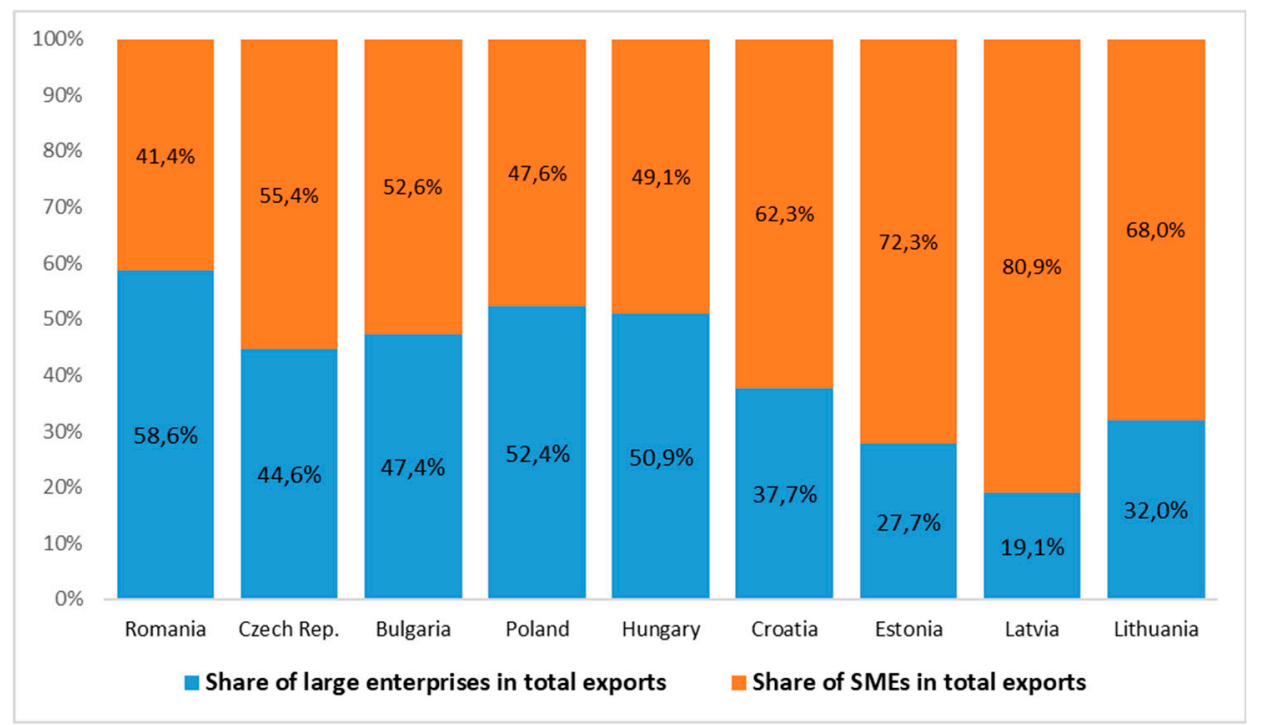

Figure 7. SMEs contribution to national exports-authors' processing based on Organization for Economic Cooperation and Development (OECD) data [17].
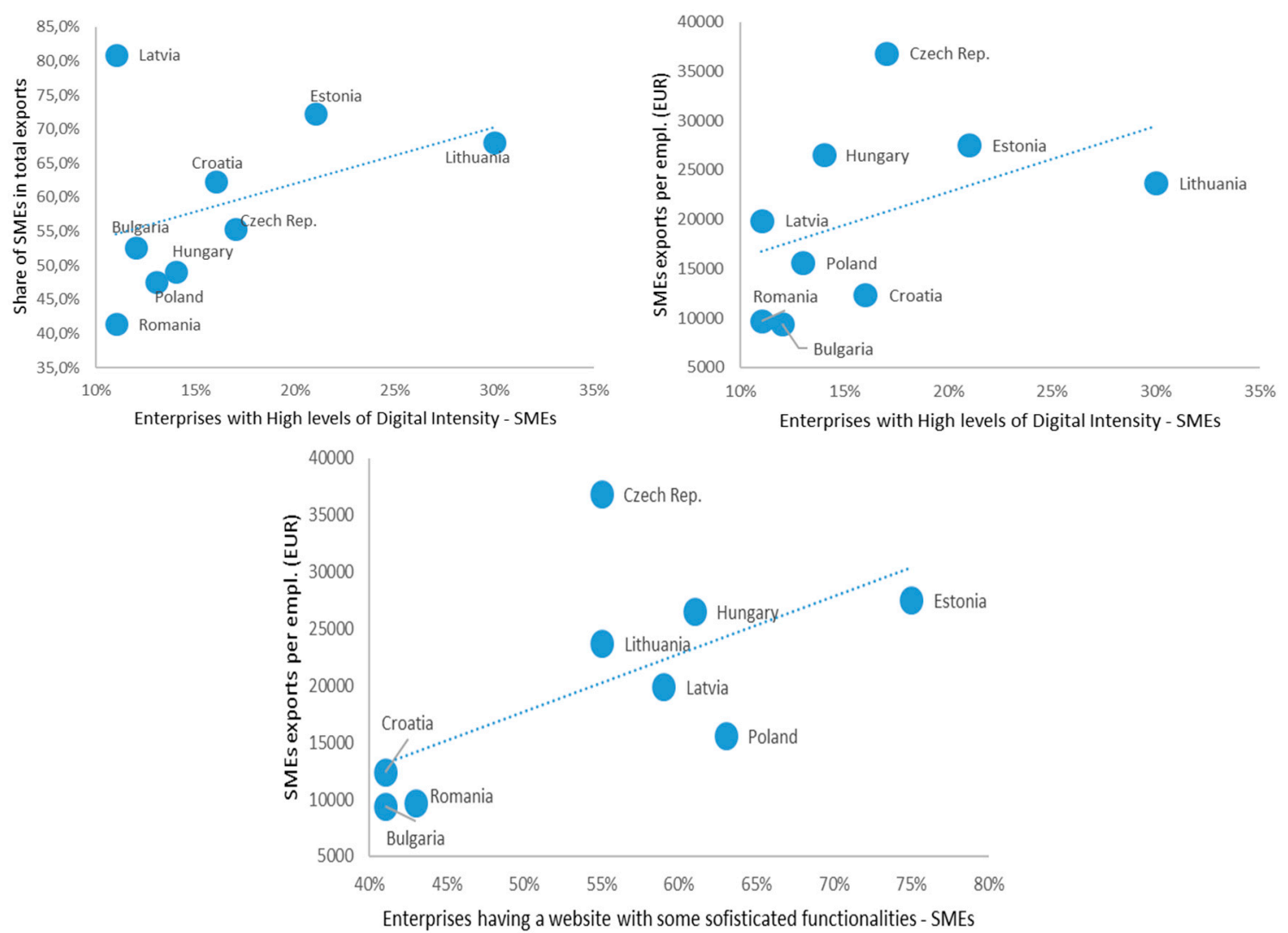

Figure 8. SMEs digitalization and exports—authors' processing based on [17-19].

The last section of the paper analyzes the impact of digitalization in terms of attractiveness to foreign capital flows, especially via mergers and acquisitions (M\&As) and private equity investment. For the number of M\&A transactions, we used data available from the United Nations Conference on Trade and Development (UNCTAD)-World Investment Report 2018, and for private equity and venture capital funds from Invest Europe. According to UNCTAD-World Investment Report 2018, "net cross-border M\&As are calculated considering sales of companies in a host economy to foreign 
multinational enterprises (MNEs). It excludes sales of foreign affiliates (already owned by foreign MNEs) to other foreign MNEs" [20] (p. 35).

Figure 9 shows the rate of M\&A transactions from 2008 to 2017 per 10.000 SMEs. It seems that the Baltic States (Estonia, Latvia and Lithuania) were the most attractive markets for M\&A after 2008, due to increased productivity and digitalization (Estonia and Lithuania) and important growth rate (Latvia). However, if we look at the average value of the transactions in Estonia and Latvia, the two Baltic countries show the lowest net value per M\&A transaction completed during this period. Additionally, as can be seen in Figure 10 there seems to be a very low correlation between the rate of M\&As per 10,000 SMEs and Digital Intensity score in the CEE9 countries.

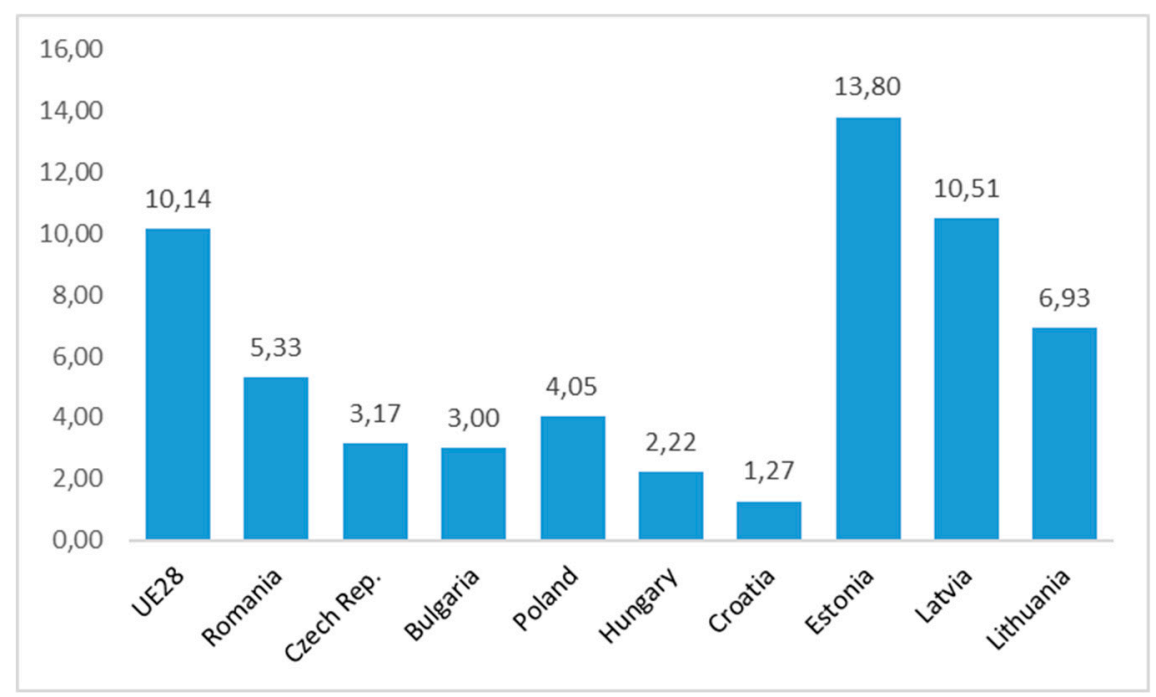

Figure 9. Mergers and acquisitions (M\&As) per 10,000 SMEs in CEE9 (2008-2017) [21].

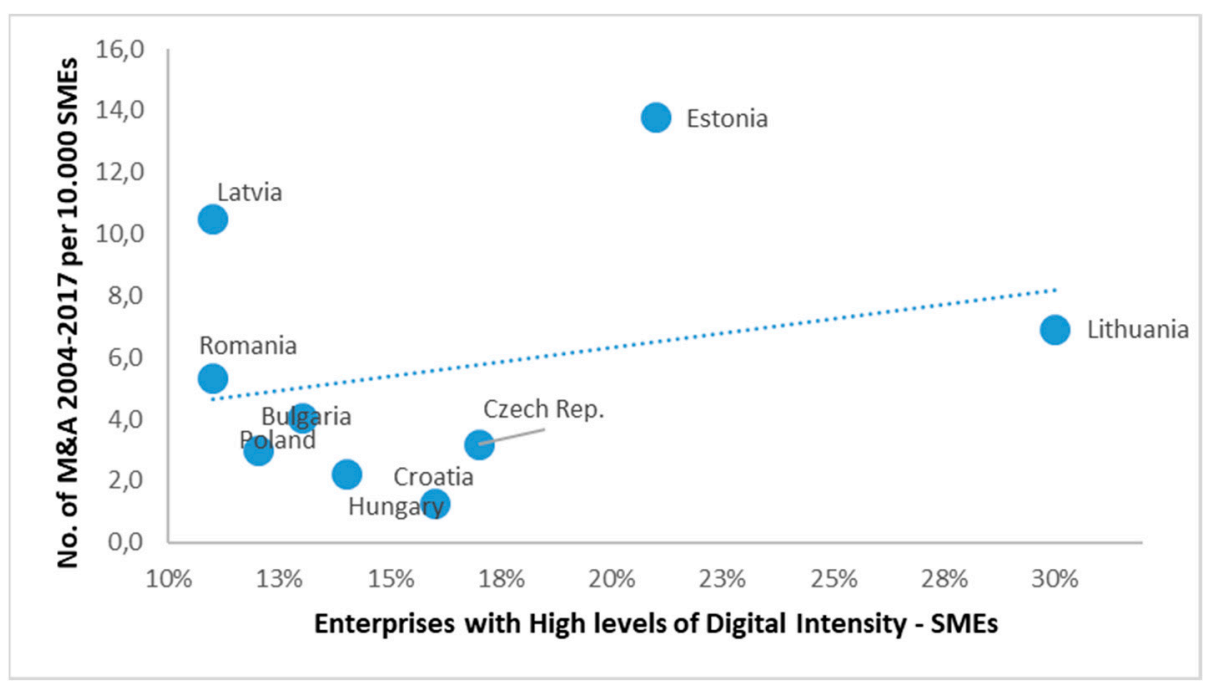

Figure 10. Relation M\&A per 10,000 SMEs—Digital Intensity score-Authors' processing based on $[18,21]$.

Close to Lithuania are Romania and Poland - quite important due to their large domestic market, while Croatia and Hungary are well below the EU28 average, displaying the lowest number of M\&A transactions per 10,000 SMEs between 2008 and 2017. Also, Czech Republic and Hungary show the highest figures in terms of net value per M\&A transaction during 2008-2017.

In absolute terms, the net value of M\&A sales in CEE9 countries represented 38.5 billion USD during 2008-2017, mostly due to the Czech Republic (11.4 billion USD) and Poland (15.2 billion USD), 
followed by Hungary ( 4.25 billion USD) and Romania (2.86 billion USD). Also, as can be seen in Figure 11, Hungary and Czech Republic have the largest net value of M\&A per transaction between 2008 and 2017, above 35 million USD, but well below the EU28 average.

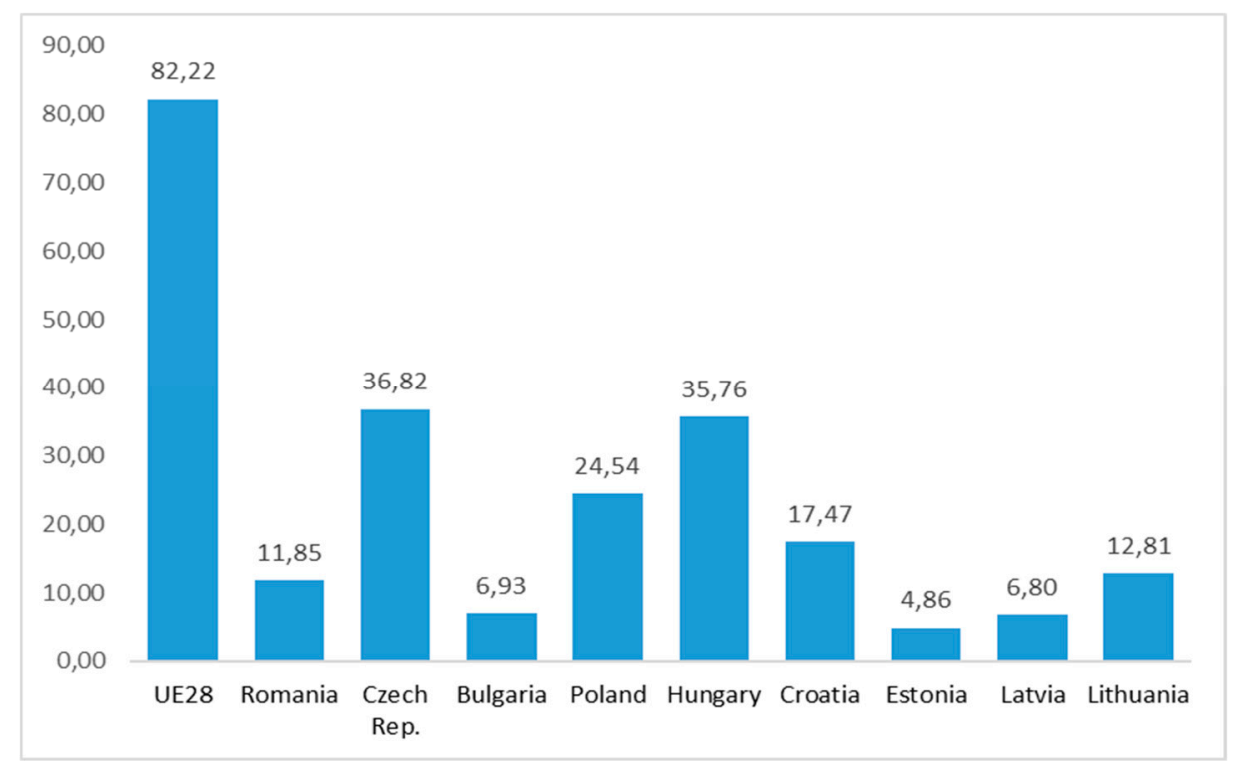

Figure 11. M\&A net value per transaction in CEE9 (2008-2017, million USD) [21].

Another investment type analyzed was private equity. In all CEE9 selected countries it reached 3.4 billion EUR in 2017, an increase of 130\% year-on-year. Invest Europe (2018) affirms that private equity growth in CEE investments underline a trend across Europe as "the total amount of European private equity investments in 2017 increased by $29 \%$ year-on-year to 71.7 billion EUR, the second highest level for Europe on record and only 4\% below 2007's peak" [21] (p. 6).

Furthermore, a total of 236 companies from CEE9 companies received private equity investments in 2017: 104 from Hungary, 60 from Poland, 20 from Bulgaria, 13 from Czech Republic, 11 from Lithuania, 10 from Romania, 8 from Estonia, 7 from Latvia, and 3 from Croatia.

Additionally, data shows that private equity investment activity in 2017 was limited to a few countries. Poland was the leading destination with $60 \%$ of the CEE9 total investment. It was followed by Romania with $12 \%$ of the CEE9 investment total value and Hungary (9\%) (Figure 12). 


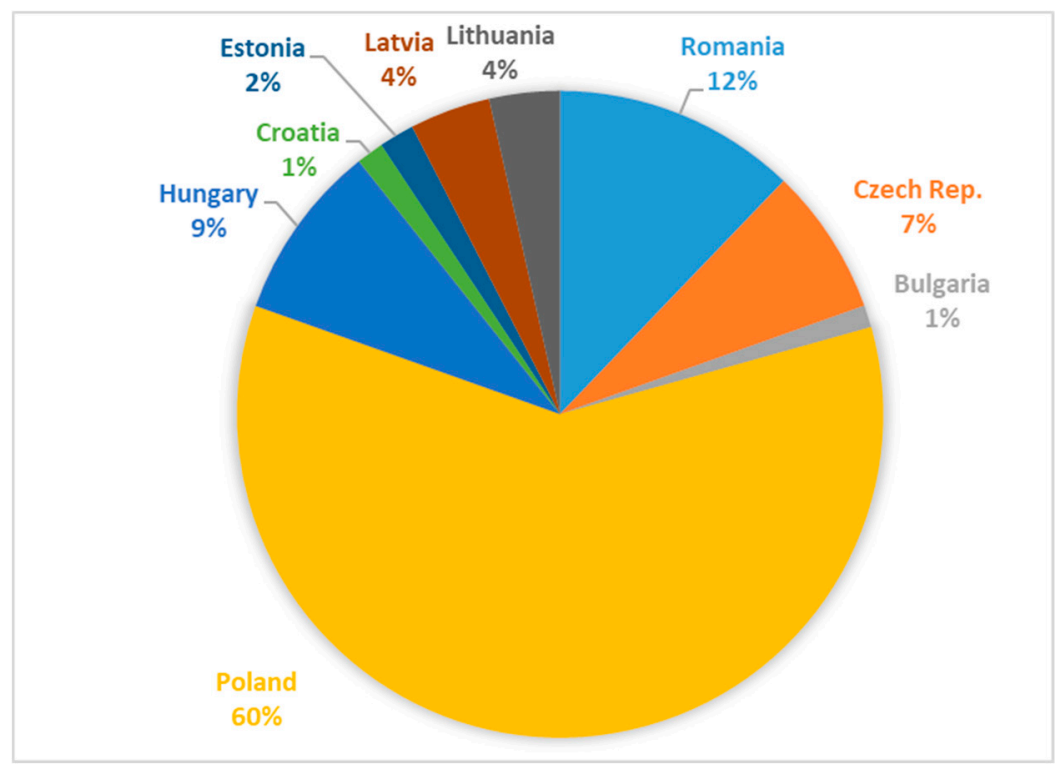

Figure 12. Private equity investment structure by country $[18,21]$.

Even though the Invest Europe report mentions that "ICT remained the strongest performing sector in terms of the number of companies receiving investment, with 90 in 2017-35\% of the CEE total—driven largely by venture capital activity" [22] (p. 16), the correlation between digital intensity of SMEs and private equity investment in CEE9 countries (as \% of GDP or private equity investment per firm) was almost non-existent in 2017. As Figure 13 shows, most private equity funds are oriented towards Latvia, Poland and Romania, countries that display a low score of digital intensity.

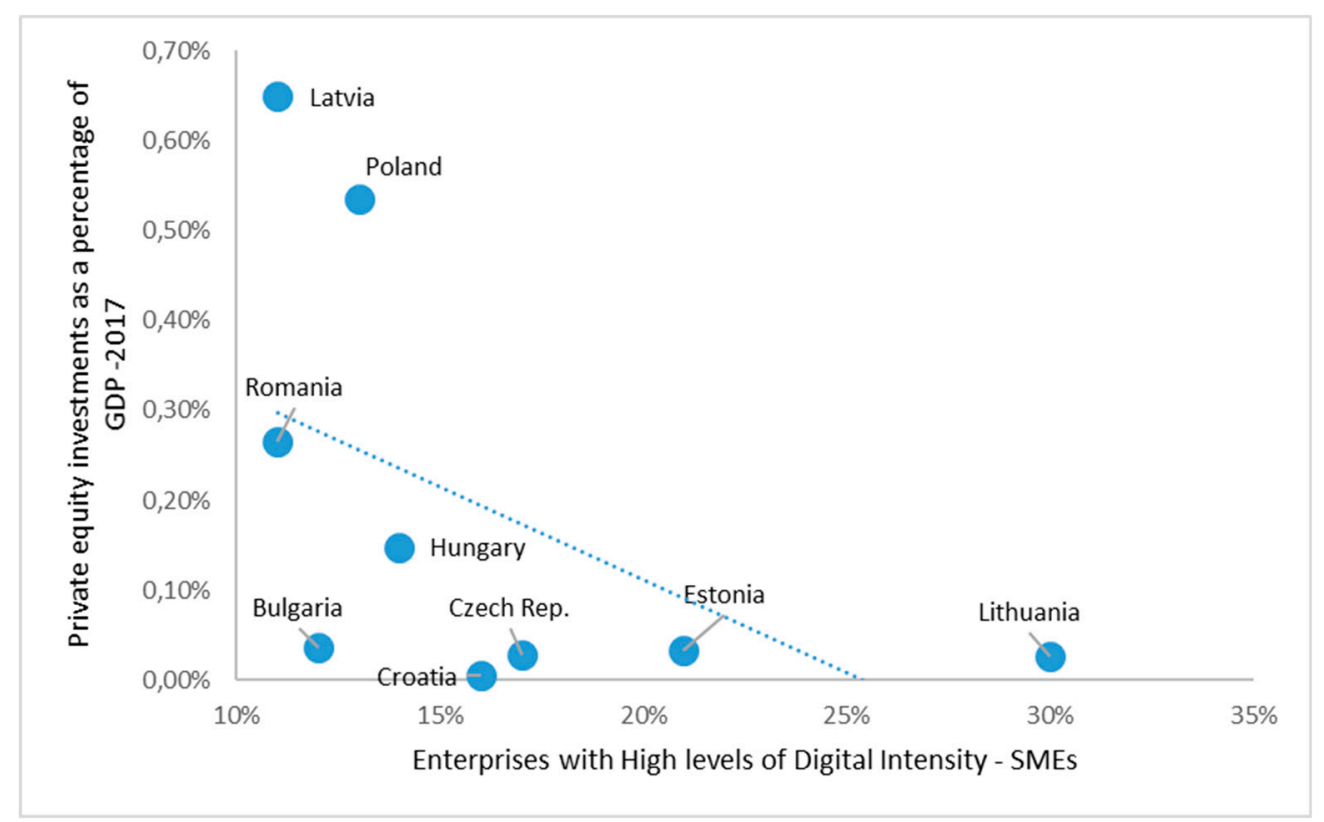

Figure 13. Private equity investments and Digital Intensity of SMEs, authors' processing based on [21].

\section{Conclusions}

Digitalization is currently one of the most important trends that change society and business. There is no doubt that the digital economy profoundly alters the companies' methods to manufacture and deliver goods and services worldwide. 
Our research states that digitalization can influence any segment of the companies' supply chain, including taxes, procurement, production, logistics and customer relations. Correspondingly, the shift towards a digital economy makes new approaches more readily available in order to increase global competitiveness and provides new prospects for business and entrepreneurship. In this paper we emphasized important aspects of how different tools of digitalization used by firms from CEE9 contribute to their economic performance.

The research hypotheses were partially validated by the data on the CEE selected countries. It seems that Assumption 1 was confirmed, the data showing that a greater intensity of digitalization for SMEs is correlated with a larger share of high-growth companies. Assumption 2 was validated, since data analysis shows that integration of digital technology into business activity improves productivity and exports at the SME level. According to our study, there seems to be a direct correlation between the exports of companies and certain tools of digitalization (i.e., sophistication of SME websites); this conclusion is valid for countries such as Hungary, Estonia or the Czech Republic. There is evidence that SMEs with high level of digital intensity have a more important contribution to national exports and we recommend SMEs that have in view to extend their activities worldwide to increase digital intensity and use of digitalization tools.

At the same time, the largest productivity gap is registered in Bulgaria ( $26 \%$ of the EU SMEs average productivity) and Romania (29\%). These are the countries with the lowest digital intensity of enterprises in the entire EU, whereas the countries with a small productivity gap against the EU average register a high digital intensity of enterprises. Our analysis shows that digitalization is an important ingredient to increase value added generated by SMEs. In this context, the link between digitalization and added value in the case of SMEs should become a more important topic for policymakers to address.

As a final point, Assumption 3 is not validated. Our research shows that there is no correlation between a higher digital technology intensity and the attractivity for foreign financial markets (M\&As and private equity investment). Also, it appears that there is a very low correlation between the rate of M\&As per 10,000 SMEs and Digital Intensity score in the CEE9. The correlation between digital intensity of SMEs and private equity investment in the CEE9 (as \% of GDP or private equity investment per firm) was almost absent in 2017. Most private equity funds were oriented towards Latvia, Poland and Romania, countries with a low score of digital intensity.

However, there are some areas that can be further analyzed to highlight the link between digitalization and SME performance, especially in terms of productivity and external competitiveness. A more comprehensive analysis of the appropriate type of digital tools to support a greater value added created by SMEs can be conducted. This analysis can be supplemented with a discussion on what tools to be used to improve export ability. A question that needs further discussions concerns the relationship between the digital intensity of SMEs and their attractivity for private equity investment in CEE countries.

Author Contributions: Conceptualization, D.L.T., G.M.Ș., D.N.S. and R.H.; Formal analysis, D.L.T., G.M.Ș., D.N.S., R.H. and G.-L.Ș.-O.; Methodology, D.L.T., G.M.Ș., D.N.S., R.H. and G.-L.S..-O.; Resources, D.L.T., G.M.Ș., D.N.S., R.H. and G.-L.Ș.-O.; Writing - original draft, D.L.T., G.M.Ș., D.N.S., R.H. and G.-L.S.-O.; Writing - review \& editing, D.L.T., G.M.S,., D.N.S., R.H. and G.-L.Ș.-O.

Funding: This research received no external funding.

Conflicts of Interest: The authors declare no conflict of interest. 


\section{Appendix A}

Table A1. Pillars of digitalization within SMEs in the European Union (EU) [22].

\begin{tabular}{|c|c|c|c|c|c|}
\hline \multicolumn{2}{|l|}{ Pillar } & \multicolumn{4}{|c|}{ Description } \\
\hline \multicolumn{2}{|c|}{ Use of enterprise resource planning (ERP) } & \multicolumn{4}{|c|}{$\begin{array}{l}\text { ERP software applications aim to facilitate the flow of information and the potential to integrate internal and } \\
\text { external management information across several functions of an enterprise. } \\
\text { ERP usually succeeds to integrate processes relevant to business planning, goods and services purchases, } \\
\text { marketing process, sales, business to consumer relationship, company finance and human resources. }\end{array}$} \\
\hline Use customer relationship mana & ement (CRM) software & \multicolumn{4}{|c|}{$\begin{array}{l}\text { Enterprises may choose to streamline their marketing efforts and target (better) their customers to maximize their } \\
\text { business potential. The adoption of CRM improves marketing and sales performance by improving customer } \\
\text { service and customer relationships. } \\
\text { Improvements come, for instance, from providing user-friendly mechanisms for receiving complaints, identifying } \\
\text { potential problems before they occur, by facilitating communication with the customer and by anticipating } \\
\text { customer preferences. These technologies enabled improvements may lead to long term customer satisfaction } \\
\text { and increased customer loyalty, decreased marketing costs, and increased sales. }\end{array}$} \\
\hline $\begin{array}{r}\text { Business processes automatically } \\
\text { customer }\end{array}$ & inked to suppliers and/or & \multicolumn{4}{|c|}{$\begin{array}{l}\text { Supply-chain management includes all activities concerning the exchange of information between an enterprise } \\
\text { and its suppliers and/or customers. This information may concern, for example, inventory levels, production } \\
\text { plans, demand and supply forecasts or progress of deliveries. Accordingly, the use of SCM software applications } \\
\text { aims to coordinate effectively the availability and delivery of products to final consumers, in the right quantity, at } \\
\text { the right time, into the right hands at optimal cost. }\end{array}$} \\
\hline \multicolumn{2}{|c|}{ Use of radio frequency identification (RFID) } & \multicolumn{4}{|c|}{$\begin{array}{l}\text { Enterprises that use radio frequency identification may automatically store and retrieve data through the use of } \\
\text { tags or transponders (devices that can be applied to or incorporated into products) so they transmit data via radio } \\
\text { waves. }\end{array}$} \\
\hline & $\begin{array}{l}\text { Share in Total EU28 } \\
\text { Enterprises }\end{array}$ & $\begin{array}{l}\text { Have Enterprise Resource } \\
\text { Planning (ERP) Software }\end{array}$ & $\begin{array}{l}\text { Use of Customer } \\
\text { Relationship Management } \\
\text { (CRM) Software }\end{array}$ & $\begin{array}{l}\text { Have Business Processes } \\
\text { Automatically Linked to } \\
\text { Suppliers and/or Customers }\end{array}$ & $\begin{array}{l}\text { Use of Radio Frequency } \\
\text { Identification (RFID) } \\
\text { Technologies }\end{array}$ \\
\hline Small enterprises (10-49 persons) & $98.9 \%$ & $28 \%$ & $30 \%$ & $15 \%$ & $9 \%$ \\
\hline $\begin{array}{l}\text { Medium-sized enterprises (50-249 } \\
\text { persons) }\end{array}$ & $0.90 \%$ & $57 \%$ & $48 \%$ & $28 \%$ & $27 \%$ \\
\hline Large enterprises (250 persons or more) & $0.20 \%$ & $76 \%$ & $62 \%$ & $47 \%$ & $44 \%$ \\
\hline Average & & 34 & 33 & 18 & 12 \\
\hline
\end{tabular}




\section{References}

1. Rüßmann, M.; Lorenz, M.; Gerbert, P.; Waldner, M.; Justus, J.; Engel, P.; Harnisch, M. Industry 4.0: The future of productivity and growth in manufacturing industries. Boston Consult. Group 2015, 9, 54-89.

2. Parviainen, P.; Tihinen, M.; Kääriäinen, J.; Teppola, S. Tackling the digitalization challenge: How to benefit from digitalization in practice. Int. J. Inf. Syst. Proj. Manag. 2017, 5, 63-77.

3. Stolterman, E.; Fors, A.C. Information technology and the good life. In Information Systems Research; Springer: New York, NY, USA, 2004; pp. 687-692.

4. Kagermann, H. Change through digitization-Value creation in the age of Industry 4.0. In Management of Permanent Change; Springer: New York, NY, USA, 2015; pp. 23-45.

5. Rachinger, M.; Rauter, R.; Müller, C.; Vorraber, W.; Schirgi, E. Digitalization and its influence on business model innovation. J. Manuf. Technol. Manag. 2018. [CrossRef]

6. Brennen, S.; Kreiss, D. Digitalization and digitization. Cult. Digit. 2014, 8.

7. Digitization, Digitalization and Digital Transformation: The Differences. Available online: https://www.iscoop.eu/digitization-digitalization-digital-transformation-disruption/ (accessed on 11 February 2019).

8. Prause, J. Digitization vs. Digitalization-Wordplay or World View? Available online: https://news.sap.com/ 2016/05/digitization-vs-digitalization-wordplay-or-world-view/ (accessed on 11 February 2019).

9. Novak, J.; Purta, M.; Marciniak, T.; Ignatowicz, K.; Rozenbaum, K.; Yearwood, K. The Rise of Digital Challengers How Digitization Can Become the Next Growth Engine for Central and Eastern Europe. 2018. Available online: https://www.mckinsey.com/ \{\}/media/McKinsey/Featured\%20Insights/Europe/Central\% 20and\%20Eastern\%20Europe\%20needs\%20a\%20new\%20engine\%20for\%20growth/The-rise-of-DigitalChallengers.ashx (accessed on 11 February 2019).

10. Parida, V.; Sjödin, D.; Reim, W. Reviewing Literature on Digitalization, Business Model Innovation, and Sustainable Industry: Past Achievements and Future Promises. Sustainability 2019, 11, 391. [CrossRef]

11. Communication from the Commission to the European Parliament, The Council, The European Economic and Social Committee and The Committee of the Regions, EUR-Lex-52016DC0180_EN_EUR-Lex. Available online: https://eur-lex.europa.eu/legal-content/EN/TXT/?uri=CELEX:52016DC0180 (accessed on 11 February 2019).

12. Tarute, A.; Gatautis, R. ICT Impact on SMEs Performance. Procedia Soc. Behav. Sci. 2014, 110, 1218-1225. [CrossRef]

13. Reichstein, C.; Härting, R.-C.; Neumaier, P. Understanding the Potential Value of Digitization for-Quantitative Research Results of European Experts. In Agents and Multi-Agent Systems: Technologies and Applications 2018: Proceedings of the 12th International Conference on Agents and Multi-Agent Systems: Technologies and Applications (KES-AMSTA-18); Jezic, G., Chen-Burger, Y.H.J., Howlett, R.J., Jain, L.C., Vlacic, L., Šperka, R., Eds.; Springer: Berlin, Germany, 2018; pp. 287-298.

14. Digital Economy and Society Index 2018 Report. Available online: https://ec.europa.eu/digital-single-market/ en/news/digital-economy-and-society-index-2018-report (accessed on 11 February 2019).

15. Alm, E.; Colliander, N.; Lind, F.; Stohne, V.; Sundström, O. Digitizing Europe: Why Northern European Frontrunners Must Drive Digitization of the EU Economy. Available online: https://www.bcg.com/en-nor/ perspectives/36553 (accessed on 11 February 2019).

16. Digital Agenda Scoreboard Key Indicators—Digital Scoreboard-Data \& Indicators. Available online: https: //digital-agenda-data.eu/datasets/digital_agenda_scoreboard_key_indicators/visualizations (accessed on 11 February 2019).

17. OECD.org-OECD. Available online: http://www.oecd.org/ (accessed on 11 February 2019).

18. Digital Agenda Key Indicators. Available online: https://virtuoso.digital-agenda-data.eu/describe/?url= http://semantic.digital-agenda-data.eu/dataset/digital-agenda-scoreboard-key-indicators (accessed on 11 February 2019).

19. Trade Map-Trade Statistics for International Business Development. Available online: https://www. trademap.org/(X(1)S(ysoc4dy25tmub555tuwubl45))/Index.aspx (accessed on 11 February 2019).

20. unctad.org|World Investment Report 2018. Available online: https://unctad.org/en/pages/publicationWebflyer. aspx?publicationid=2130 (accessed on 11 February 2019). 
21. InvestEurope, Special Paper on Private Equity Activity in Central and Eastern Europe 2017, Central and Eastern Europe Statistics. July 2018. Available online: https:/www.investeurope.eu/media/727455/InvestEurope-CEE-Activity-Report-2017-05072018.pdf (accessed on 11 February 2019).

22. E-business Integration. Available online: https://ec.europa.eu/eurostat/statistics-explained/index.php/Ebusiness_integration\#Enterprise_resource_planning_.28ERP.29 (accessed on 11 February 2019).

(C) 2019 by the authors. Licensee MDPI, Basel, Switzerland. This article is an open access article distributed under the terms and conditions of the Creative Commons Attribution (CC BY) license (http://creativecommons.org/licenses/by/4.0/). 